\title{
Single-cell microinjection assay indicates that 7-hydroxycoumarin induces rapid activation of caspase-3 in A549 cancer cells
}

\author{
MARIBEL SOTO-NUÑEZ ${ }^{1}$, KAREN AZUCENA DÍAZ-MORALES ${ }^{1}$, PATRICIA CUAUTLE-RODRÍGUEZ ${ }^{2}$, \\ VÍCTOR TORRES-FLORES ${ }^{1}$, JOSÉ SULLIVAN LÓPEZ-GONZÁLEZ ${ }^{3}$, \\ JUAN JOSÉ MANDOKI-WEITZNER ${ }^{1}$ and JUAN ARCADIO MOLINA-GUARNEROS ${ }^{1}$ \\ ${ }^{1}$ Department of Pharmacology, School of Medicine; ${ }^{2}$ Research Division, School of Medicine, \\ National University of Mexico, Mexico City 04510; ${ }^{3}$ Department of Chronic-Degenerative Diseases, \\ National Institute of Respiratory Diseases 'Ismael Cosio Villegas', Mexican Ministry of Health, \\ Mexico City 14080, Mexico
}

Received May 9, 2015; Accepted September 1, 2015

DOI: 10.3892/etm.2015.2765

\begin{abstract}
Coumarins have attracted intense interest in recent years due to their apoptogenic effects. The aim of the present study was to determine whether 7-hydroxycoumarin (7-HC) induces changes in caspase-3 (C-3) activity in A549 human lung carcinoma cells. A range of analytical techniques, including colorimetric and fluorometric assays, western blotting, single-cell microinjection, fluorescence microscopy and image analysis were conducted to elucidate the effects of 7-HC. A 24-h exposure to $1.85 \mathrm{mM} 7-\mathrm{HC}$ induced a $65 \%$ increase in $\mathrm{C}-3$ activity, and a notable conversion of procaspase-3 to $\mathrm{C}-3$, in addition to poly(ADP-ribose)polymerase cleavage. Furthermore, morphological changes associated with apoptosis were observed. Exposure of the cells to 7-HC for 3 or $6 \mathrm{~h}$ increased calcium conductance by $27 \%$. By performing the single-cell microinjection of a specific fluorescent substrate of C-3 into previously 7-HC-exposed cells, a typical enzymatic kinetic profile of $\mathrm{C}-3$ activation was identified a number of hours prior to the morphological and biochemical changes associated with apoptosis being observed. These results suggest that the rapid in vivo activation of C-3 is induced by $7-\mathrm{HC}$, the most relevant biotransformation product of coumarin in humans.
\end{abstract}

Correspondence to: Dr Juan Arcadio Molina-Guarneros, Department of Pharmacology, School of Medicine, National University of Mexico, Building 'D', First floor, Circuito escolar s/n, Ciudad Universitaria, Av. Universidad 3000, Colonia Universidad Nacional Autónoma de México, Mexico City 04510, Mexico E-mail: molina_ja2007@yahoo.com.mx

Key words: apoptosis, caspase-3, 7-hydroxycoumarin, microinjection, A549 cells

\section{Introduction}

Lung cancer is a global public health issue. In the USA, cancer of the lung and bronchus represents $13.5 \%$ of all new cancer cases. The estimated number of new cases for 2014 in the USA is 224,210 and the estimated number of patients that will succumb to these diseases is 159,260 (1). The US National Cancer Institute defines targeted cancer therapies as drugs or other substances that interfere with specific molecules associated with cancer cell growth and survival. Targeted cancer therapies that have been approved for use include agents that prevent cell growth signaling, interfere with the development of tumor-supplying blood vessels, induce cancer cell death, stimulate the immune-mediated destruction of cancer cells and/or deliver toxic drugs to cancer cells. These therapies are frequently cytostatic, blocking tumor cell proliferation. At present, targeted therapies are the focus of copious anticancer drug development research efforts, which aim to identify of targets that are crucial to cancer cell growth and survival (2).

The US Food and Drug Administration (FDA) approved coumarin as an orphan drug for the treatment of renal cell carcinoma on December 22, 1994 (3). The name coumarin is derived from the word coumarou, an alternative name for the tonka bean (Dipteryx odorata Willd., Fabaceae). Chemically, coumarins have a benzopyrone structure. Umbelliferone, esculetin and scopoletin are the most widespread coumarins in nature (4). Coumarins have been investigated as potential treatments for various clinical conditions, such as high protein edema (5), chronic infections (6,7) and cancer (8-10). The apoptogenic properties of coumarins have attracted intense interest in recent years. The induction of apoptosis by natural (11-18) and synthetic (19-21) coumarins has been reported in human leukemia cells, lung carcinoma cell lines, adipocytes, HeLa cells, hepatocellular carcinoma, human neuroblastoma cell lines and human prostate cancer cell lines. The induction of apoptosis occurs via mitochondrial pathways, including the modulation of the NF- $\mathrm{NB}$, mitogen-activated protein kinase (MAPK) and p53 pathways, which subsequently activate caspase-3 (C-3)-dependent mechanisms. The downregulation of Rho GTPases (RhoGDI $\alpha$ ) by a coumarin derivative 
through transcriptomic and proteomic mechanisms (22) has been described. A previous study (12) observed that the A427 lung carcinoma cell line exhibited increases in the proportion of Annexin-V-positive cells of 50 and $83 \%$ compared with solvent-treated cells (estimated using flow cytometry), when exposed to $100 \mu \mathrm{g} / \mathrm{ml}$ coumarin and 7-hydroxycoumarin (7-HC), respectively, for $4 \mathrm{~h}$.

The aim of the present study was to determine whether changes in C-3 activity are induced in a single live A549 human lung carcinoma cell by treatment with 7-HC, the primary human biotransformation product of coumarin (23), by performing the single-cell microinjection of a C-3 substrate.

\section{Materials and methods}

Reagents. A549 lung carcinoma cells (CRM-CCL-185) were obtained from American Type Culture Collection (Rockville, MD, USA). Ionomycine and RPMI-1640 medium were purchased from Gibco Life Technologies (Carlsbad, CA, USA). Fetal bovine serum (FBS) was obtained from GE Healthcare Life Sciences (Logan, UT, USA). MTT, 5-bromo-4-chloro-3'-indolyl phosphate/nitro-blue tetrazolium chloride (BCIP/NBT), ethylene glycol-bis ( $\beta$-aminoethyl ether)-N,N,N',N'-tetraacetic acid (EGTA) tetrasodium salt and a caspase-3 colorimetric assay kit were purchased from Sigma-Aldrich (St. Louis, MO, USA). Monoclonal anti-caspase 3 clone 4-1-18 (\#MA1-16843) and monoclonal anti-poly (ADP-ribose) polymerase (PARP) clone 123 antibodies (\#43600) were obtained from Zymed Laboratories, Inc. (San Francisco, CA, USA). Rhodamine 110, bis-( $N$-CBZ-L-aspartyl-L-glutamyl-L-valyl-L-aspartic acid amide) (Z-DEVD-R110) was purchased from Invitrogen Life Technologies (Camarillo, CA, USA). Borosilicate glass capillaries (1B100F-4) were obtained from World Precision Instruments, Ltd. (Sarasota, FL, USA). Dextran-Texas Red [3,000 molecular weight (MW)], dextran-fluorescein isothiocyanate (FITC) (3,000 MW) and Fura-2AM dyes were purchased from Molecular Probes Life Technologies (Carlsbad, CA, USA). Tissue culture flasks $\left(80 \mathrm{~cm}^{2}\right)$ and 6-well multidishes were obtained from Nunc A/S (Roskilde, Denmark). A 35x10-mm polystyrene dish was purchased from Corning, Inc. (New York, NY, USA).

Cell culture. A549 human lung carcinoma cells were cultured at $37^{\circ} \mathrm{C}$ in $5 \% \mathrm{CO}_{2}$ using RPMI-1640 medium, supplemented with a $10 \%$ heat-inactivated FBS. Cells were sub-cultured through trypsinization, seeded at $2 \times 10^{5}$ cells/well in 6 -well boxes or Petri dishes, and left to affix for $24 \mathrm{~h}$ prior to exposure to ethanol or a solution of 7-HC in ethanol. In each case the final solvent concentration was $3 \%$.

Cell viability assay. The viability of the cell line was determined using an MTT assay (24). Cells were seeded at a density of $5 \times 10^{3}$ cells/100 $\mu 1$ RPMI-1640 in a 96-well microplate. Cells were treated with ethanol (control) or a solution of 7-HC in ethanol $(1.85 \mathrm{mM})$ for $24 \mathrm{~h}$. The final concentration of ethanol was $3 \%(\mathrm{v} / \mathrm{v})$. The number of viable cells was estimated by treatment with $20 \mu \mathrm{l} /$ well MTT $(5 \mathrm{mg} / \mathrm{ml})$ for $4 \mathrm{~h}$, enabling the mitochondrial succinate dehydrogenase in viable cells to reduce MTT to purple formazan crystals. The medium was aspirated and $100 \mu \mathrm{l}$ dimethyl sulfoxide (DMSO)/well was added. Crystals were dissolved in DMSO and the absorbance at $570 \mathrm{~nm}$ was measured using an ELx800 microplate reader (Biotek Instruments, Inc., Winooski, VT, USA). The percentage inhibition of cell viability (\%IC) was measured using the following formula: \% IC $=[(1-$ absorbance of cells treated with 7-HC in ethanol/absorbance of cells in ethanol) $x$ 100].

Colorimetric assay to determine the time course and concentration response of $C-3$ activity. To evaluate the concentration response, A549 cells were exposed to ethanolic solutions of 7-HC $(0.61,1.23$ or $1.85 \mathrm{mM})$ for 24 -h with three replicates per concentration. In order to determine the time course, A549 cells were exposed to a $1.85-\mathrm{mM}$ ethanolic solution of 7-HC for 6, 12 or $24 \mathrm{~h}$. Cell lysates were obtained (as described below) and an endpoint colorimetric method based on peptide hydrolysis (Ac-DEVD-pNA) was employed (Novex Caspase-3 Colorimetric Protease Assay Kit; Thermo Fisher Scientific, Waltham, MA, USA) and the absorbance at $405 \mathrm{~nm}$ was measured using an ELx800 microplate reader. The mean value of the solvent-treated cell absorbance was calculated for use as a basal reference. Response-increase percentages of the different drug exposures were determined and plotted as the C-3 enzymatic activity index: Ratio of C-3 activity = [optical density (OD) treatment/OD control treatment] x 100.

Protein isolation and quantitation. Following each cell treatment, cell lysates were obtained using a lysis buffer containing $20 \mathrm{mM}$ Tris, $150 \mathrm{mM} \mathrm{NaCl}, 1 \mathrm{mM} \mathrm{NaOH}, 1 \mathrm{mM}$ ethylenediaminetetraacetic acid, $1 \mathrm{mM}$ EGTA and 1\% Triton X-100. The protein concentration was estimated using a Micro BCA Protein assay kit (Pierce Biotechnology, Inc., Rockford, IL USA).

Concentration-response assays. In 6-well multidishes $1.5 \times 10^{6}$ A549 cells were let to affix in three RPMI-1640 replicates, then exposed to $0.3,0.6,0.92$ or $1.85 \mathrm{mM} 7-\mathrm{HC}$ or ethanol for $24 \mathrm{~h}$.

Time course assays. Next, $1.5 \times 10^{6}$ A549 cells were triplicated, then exposed to either ethanol or $1.85 \mathrm{mM}$ ethanol-dissolved 7-HC for 6, 12, 18 or $24 \mathrm{~h}$. In each case the final solvent concentration was $3 \%$. The procedure was completed as described in the protein isolation and quantitation section.

Western blot analysis. Protein expression was determined by conducting electrophoresis using a polyacrylamide gel (SDS-PAGE) at $15 \%$. Proteins were then transferred at $25 \mathrm{~V} / 300 \mathrm{~mA}$ to polyvinylidene fluoride membranes. Procaspase-3, C-3 and PARP expression levels were determined by incubating the membranes with primary antibodies $(1.5 \mu \mathrm{g} / \mathrm{ml})$ against caspase-3 (1:250) and PARP (1:1,000) overnight at $5^{\circ} \mathrm{C}$. Membranes were then stir-washed three times for $10 \mathrm{~min}$ in phosphate-buffered saline (PBS). Subsequently, goat anti-mouse IgG-biotin secondary antibodies (1:10,000; Sigma-Aldrich) for $1 \mathrm{~h}$ at $37^{\circ} \mathrm{C}$. ExtrAvidin-Alkaline Phosphatase $(0.15 \mu \mathrm{g} / \mathrm{ml}$; Sigma-Aldrich) with BCIP/NBT solution (Roche Diagnostics, Basel, Switzerland) was used to visualize the membranes. Western blot assays were conducted in triplicate and analyzed using densitometry (Molecular Imager Gel Doc and ChemiDoc systems) using Quantity One 
1-D analysis software, version 4.6.9 (Bio-Rad Laboratories, Inc., Hercules, CA, USA).

Observation of morphological changes indicating apoptosis. A549 cells were exposed to an $1.85 \mathrm{mM}$ solution of 7-HC in ethanol or $3 \%$ ethanol for 6,12 or $24 \mathrm{~h}$ with three replicates. Phase contrast images were captured using an Eclipse TS100 inverted microscope and a DXM1200c camera (Nikon Corporation, Tokyo, Japan) at a magnification of $\mathrm{x} 400$.

Calcium influx measurement. In order to determine calcium influx, $3 \times 10^{6} \mathrm{~A} 549$ cells were exposed in three replicates to an ethanolic solution of 7-HC ( 0.9 or $1.85 \mathrm{mM} 7-\mathrm{HC})$ for 3 , 6 and $12 \mathrm{~h}$ (data for $12 \mathrm{~h}$ not shown as the results were not significantly different). Cells were loaded for $40 \mathrm{~min}$ at $37^{\circ} \mathrm{C}$ with $4 \mu \mathrm{M}$ Fura-2 AM. The cells were subsequently centrifuged at $300 \mathrm{x}$ g for $5 \mathrm{~min}$ in $5 \mathrm{ml}$ PBS. The pellet $(100 \mu \mathrm{l})$ was immediately added to a heated cuvette $\left(37^{\circ} \mathrm{C}\right)$ containing $2.5 \mathrm{ml}$ PBS, which was constantly stirred with a magnetic bar. Ionomycine was used as positive control. Next, 6 mM EGTA was used to chelate the calcium. The fluorescence was detected at $488 \mathrm{~nm}$ using an optical filter (Andover Corporation, Salem, NH, USA), alternately exciting Fura-2 AM at 340/380 nm using a monochromator purchased from Photon Technology International (PTI; Monmouth Junction, NJ, USA). Data were acquired and digitized at $0.83 \mathrm{~Hz}$ using the PTI interface.

Single-cell microinjection. Cell microinjection (25) was performed using the Nikon Eclipse TS100 inverted microscope (Nikon Corporation, Tokyo, Japan) equipped with a programmable IM-300 microinjector and an MHW-3 hydraulic micromanipulator (Narishige International, Ltd., London, UK). Microinjection needles were crafted using borosilicate glass capillaries using a P-87 device (Sutter Instrument Co., Novato, CA, USA). Microinjection needles were loaded using Eppendorf microloaders (Eppendorf AG, Hamburg, Germany). Microinjection time and pressure parameters were determined using $0.1 \%$ dextran-FITC $(3,000 \mathrm{MW})$ microinjection solution. The optimal injection time was determined as being between 200 and $400 \mathrm{msec}$, while the optimal microinjection pressure was $6.5 \mathrm{psi}$. In order to determine the basal activity of C-3, the specific substrate Z-DEVD-R110 was microinjected at a concentration of $1.3 \mathrm{mg} / \mathrm{ml}$ into single cells. Images were captured using a DXM-1200C camera (Nikon Corporation).

For each assay, A549 cells were incubated for 3, 6, 12, 18 and $24 \mathrm{~h}$ with a $1.85 \mathrm{mM}$ solution of 7-HC in ethanol or $3 \%$ ethanol (data for $18 \mathrm{~h}$ not shown as the results were not significantly different). Then, culture medium was withdrawn from the Petri dish and the cells were washed twice with $1 \mathrm{ml}$ PBS. Finally, the cells were resuspended in $1 \mathrm{ml}$ PBS and the microinjection of Z-DEVD-R110 into single cells was performed.

Image analysis. Prior to microinjection, images were captured at $\times 400$ magnification in phase contrast and green fluorescence $(520 \mathrm{~nm})$ to act as the negative control. Following the microinjection of the substrate, images were captured using a red filter at $615 \mathrm{~nm}$. Immediately after this, fluorescence images were captured every $20 \mathrm{sec}$ for $10 \mathrm{~min}$. This method was standardized by determining the fluorescence intensity changes in each
A

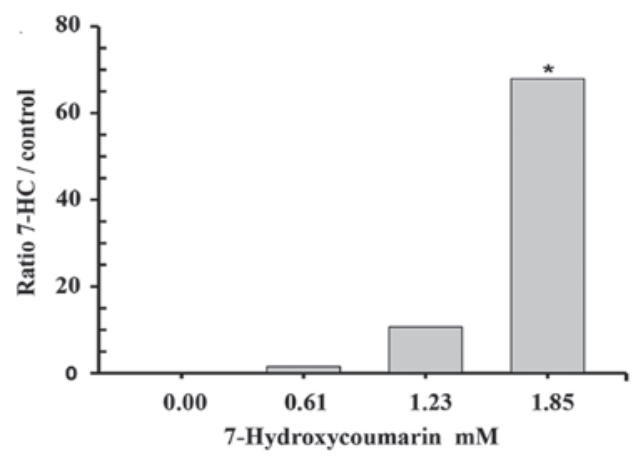

B

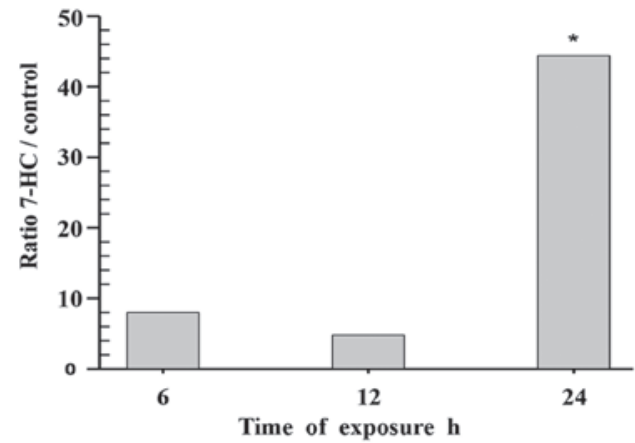

Figure 1. Colorimetric assays based on peptide (Ac-DEVD-pNA) hydrolysis were conducted to estimate caspase-3 activity in cell lysates from A549 cells exposed to 7-HC. Results shown are the percentage increase relative to the control group. (A) Concentration-response curve after $24 \mathrm{~h}\left({ }^{*} \mathrm{P}<0.01\right.$ vs control). (B) Time course of $1.85 \mathrm{mM}$ exposure ( $\mathrm{P}<0.05$ vs. control). 7-HC, 7-hydroxycoumarin.

image. Digital images were obtained using NIS-Elements AR software, version 3 (Nikon Corporation), which was calibrated for use with a $\mathrm{x} 40$ lens. The C-3 activation dynamic was then analyzed in the various cell exposure groups.

Statistical analysis. Plots were generated and statistical analysis was performed using SigmaPlot for Windows, version 11.0 and SigmaStat, version 3.5 (Systat Software, Inc., San Jose, CA, USA). Analysis of variance tests were performed, and if a statistically significant difference was identified to isolate the group or groups that differ from the others then a multiple comparison versus control group (Dunnett's method) test was used. $\mathrm{P}<0.05$ was considered to indicate a statistically significant result.

\section{Results}

Treatment with 7-HC reduces cell viability and increases C-3 activity in a time-dependent manner. A549 cells were incubated with 7-HC and MTT assays were performed to determine the cell viability. A $10 \%$ reduction in cell viability was observed following a 3-h exposure to $1.85 \mathrm{mM}$ 7-HC; the cell viability further decreased by $30 \%$ after $12 \mathrm{~h}$ and $\sim 40 \%$ after $24 \mathrm{~h}$ (data not shown).

The concentration-response of $\mathrm{C}-3$ to $7-\mathrm{HC}$ was obtained using endpoint colorimetric assays of the cell lysates. A statistically significant increase ( $\mathrm{P}=0.009$, Dunnett's method) in enzymatic activity (65\%) was observed compared with the control group when the cells were incubated with $1.85 \mathrm{mM}$ 7 - $\mathrm{HC}$ for $24 \mathrm{~h}$. The time course of treatment with $1.85 \mathrm{mM}$ 


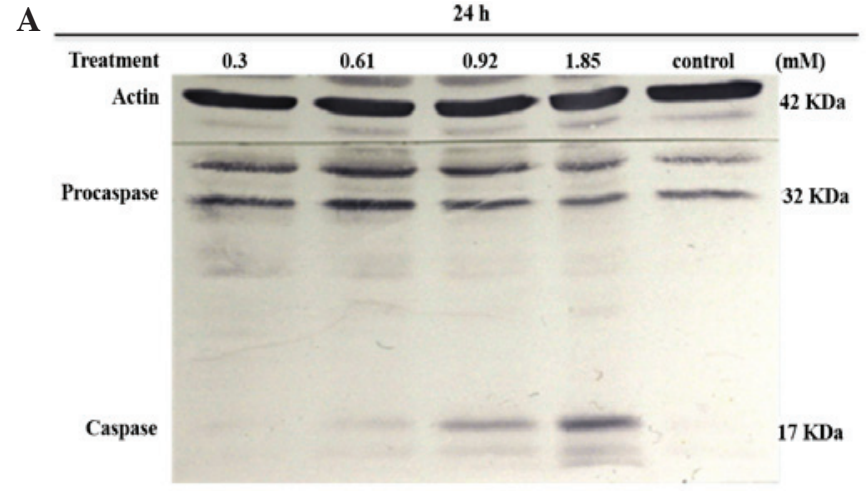

B

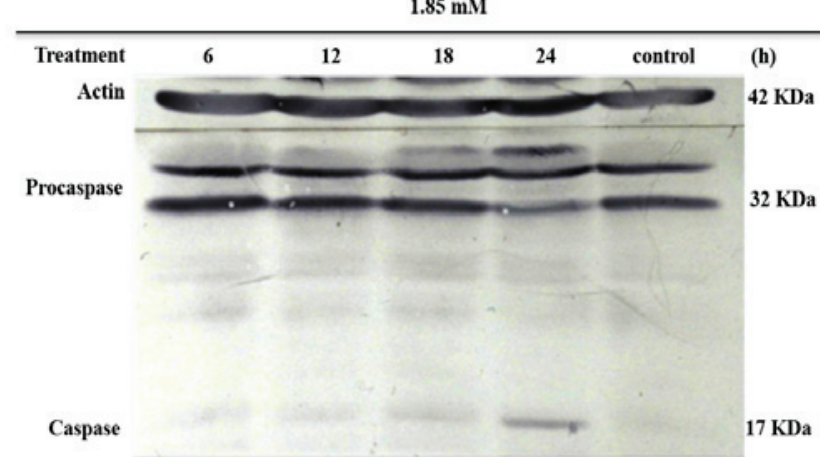

C

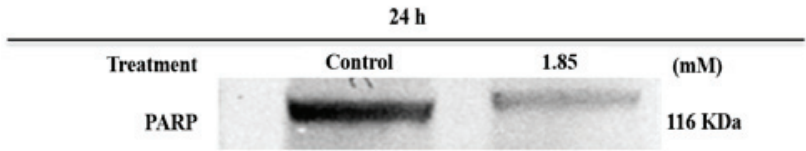

Figure 2. Representative western blots showing changes in the protein levels of A549 cell lysates following 7-HC treatment. The A549 cells $\left(1.5 \times 10^{6} / \mathrm{ml}\right)$ were treated with $0.3,0.6,0.9$ and $1.85 \mathrm{mM} 7-\mathrm{HC}$ or ethanol for $24 \mathrm{~h}$. Lysates were prepared and determined as described in Materials and methods. Representative western blots for procaspase-3 and caspase-3 (A) for cells treated with different concentrations of 7-HC for $24 \mathrm{~h}$ and (B) following exposure of the cells to $1.85 \mathrm{mM} 7-\mathrm{HC}$ for various treatment times. (C) PARP degradation was observed after $24 \mathrm{~h}$ of exposure to $1.85 \mathrm{mM}$ 7-HC. PARP, poly (ADP-ribose) polymerase; 7-HC, 7-hydroxycoumarin.

7-HC was evaluated, with measurements taken after 6 , 12 and $24 \mathrm{~h}$ of exposure. The cells exposed to $1.85 \mathrm{mM} 7-\mathrm{HC}$ for $24 \mathrm{~h}$ exhibited a statistically significant difference in C-3 activity compared with the control $(\mathrm{P}<0.05$, Dunnett's method; Fig. 1).

7-HC increases the cleavage of procaspase-3 to $C-3$ in a time-dependent manner. After $24 \mathrm{~h}$ of exposure to various concentrations of 7-HC, lysates were obtained and subjected to gel electrophoresis in denaturing conditions. Subsequently, the levels of procaspase-3, C-3 and PARP were evaluated using western blot analysis. Bands for procaspase-3 and cleavage product $\mathrm{C}-3$ were immunodetected in the cells that were treated with 0.92 and $1.85 \mathrm{mM} 7-\mathrm{HC}$, but C-3 bands were not detected for the control (ethanol-treated) cells (Fig. 2A).

Treatment with $1.85 \mathrm{mM} 7-\mathrm{HC}$ did not induce the conversion of procaspase-3 into C-3 until the cells had been subjected to $24 \mathrm{~h}$ of exposure (Fig. 2B). Furthermore, the cells exposed to $1.85 \mathrm{mM}$ 7-HC exhibited the characteristic activity of C-3 in the cleavage of PARP (Fig. 2C).

Furthermore, only $12 \mathrm{~h}$ of exposure to $1.85 \mathrm{mM} 7-\mathrm{HC}$ induced characteristic apoptotic changes in the cells, such as blebbing and shrinking, which were not observed in the control or RPMI-1640 (untreated) cells (Fig. 3).

7-HC exposure increases calcium conductance in A549 cells. The effects of 7-HC on calcium conductance in A549 cells were investigated. It was observed that a 3-h exposure to $0.9 \mathrm{mM} 7-\mathrm{HC}$ significantly increased calcium conductance by $17 \%$, while exposure to $1.85 \mathrm{mM} 7-\mathrm{HC}$ for the same time period increased conductance by $27 \%(\mathrm{P}<0.05)$ compared with that in the control group (Fig. 4A). Similarly, a 6-h exposure to $0.9 \mathrm{mM} 7-\mathrm{HC}$ increased conductance by $12 \%$, while exposure to $1.85 \mathrm{mM} 7-\mathrm{HC}$ for the same time period increased conductance by $27 \%(\mathrm{P}<0.05)$ compared with that in the control group (Fig. 4B).

7-HC exposure increases the activity of caspase-3 in single cells. Finally, single-cell microinjection assays were performed on cells that had been exposed to ethanol or $1.85 \mathrm{mM} 7-\mathrm{HC}$ for $3,6,12,18$ and $24 \mathrm{~h}$ and time course curves were prepared. The process was documented by capturing digital images every 5 sec over a 10-min period (Fig. 5A and B). Following the analysis of similar areas in each cell by measuring the intensity/pixel ratio using green fluorescence, the mean values were plotted (Fig. 5C). In each curve a phase of exponential increase was evident, followed by a plateau and an exponential phase of fluorescence reduction. Comparisons of the initial velocities through linear regression indicated that the real regression corresponds to $7-\mathrm{HC}$ (slope $>0$ ), while the control had no slope $>0$. Thus, the results indicated the presence of typical first order enzymatic kinetics corresponding to C-3.

\section{Discussion}

In a previous study, it was demonstrated using flow cytometry that the exposure of A427 human lung adenocarcinoma cells to $0.98 \mathrm{mM} 7-\mathrm{HC}$ for 4-6 h, produced an $83 \%$ increase of Annexin-V-positive cells (12). In the present study, the inductive effect of 7-HC on $\mathrm{C}-3$ activity in cellular lysates was demonstrated to occur in a concentration-dependent manner, and the optimal exposure time to obtain the maximum enzymatic activity was identified. Furthermore, the results of western blot analysis demonstrated the expression of procaspase-3 in the cells and its conversion into $\mathrm{C}-3$ in a concentration- and time-dependent manner, in addition to the proteolytic cleavage of PARP by C-3, as described by Yang et al (13). Morphological changes associated with apoptosis were identified, such as blebbing and shrinking, comparable to the apoptotic bodies reported by Chuang et al (14) and Elinos-Báez et al (26). Chuang et al (14) reported a significant increase in calcium flux in HeLa cells treated for $24 \mathrm{~h}$ with $25-100 \mu \mathrm{M}$ coumarin, using flow cytometry. Through fluorescence spectrometry, in the present study this effect was detected at a higher (millimolar) concentrations of 7-HC in cells exposed for $3 \mathrm{~h}$. Furthermore, in the present study, experiments were conducted to determine how rapidly the exposure of A549 cells to 7-HC induced the activation of 

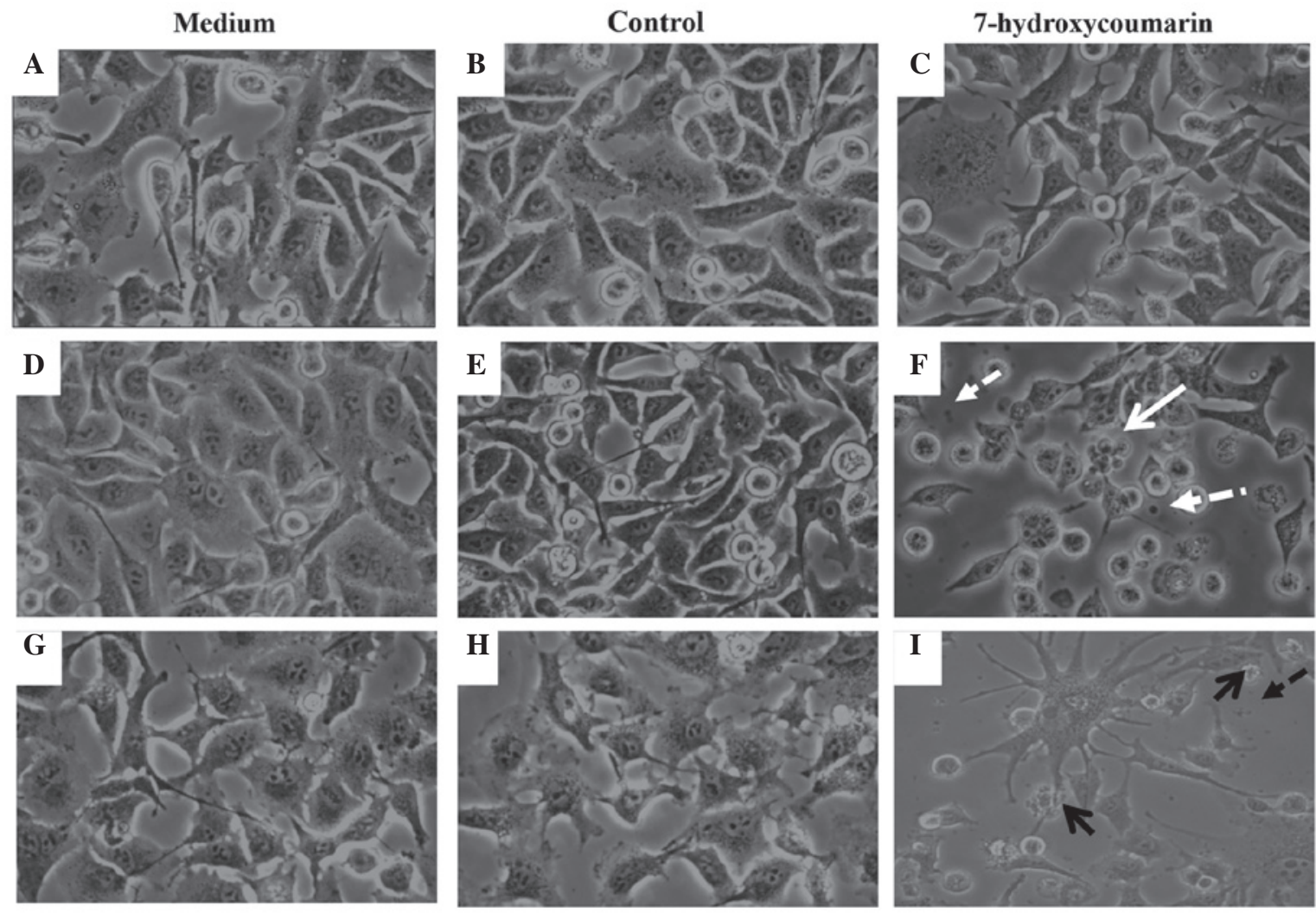

Figure 3. Phase contrast microscopy images (magnification, $\mathrm{x} 400$ ) showing differences in A549 cell morphology following treatment with RPMI-1640 (medium), 3\% ethanol (control) and a $1.85 \mathrm{mM}$ solution of 7-hydroxycoumarin in ethanol. Images of the cells were captured at (A-C) 6 , (D-F) 12 and (G-I) 24 h. Morphological changes associated with apoptosis included blebbing (indicated by continuous arrows) and apoptotic bodies (indicated by discontinuous arrows).

A
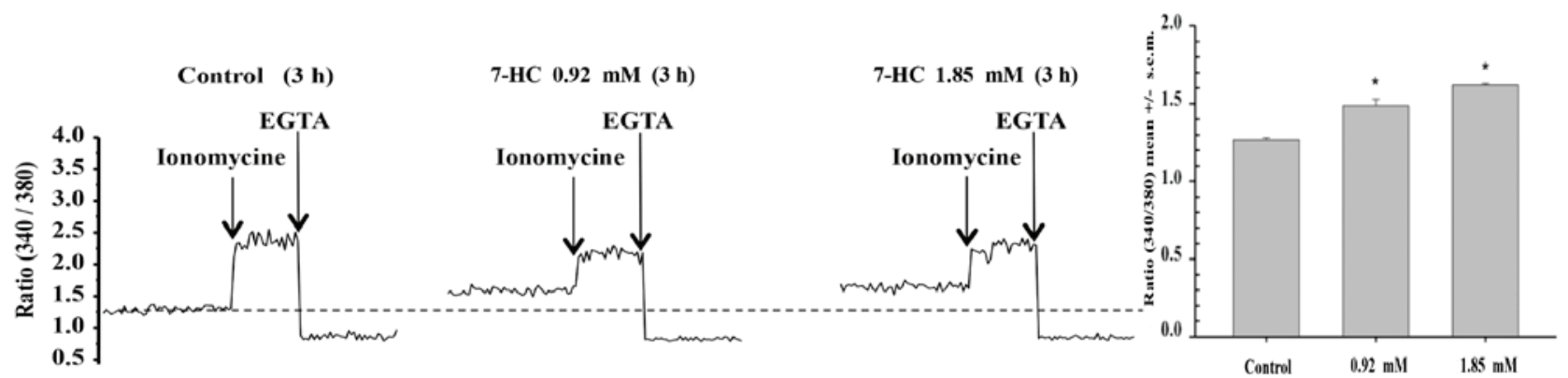

B
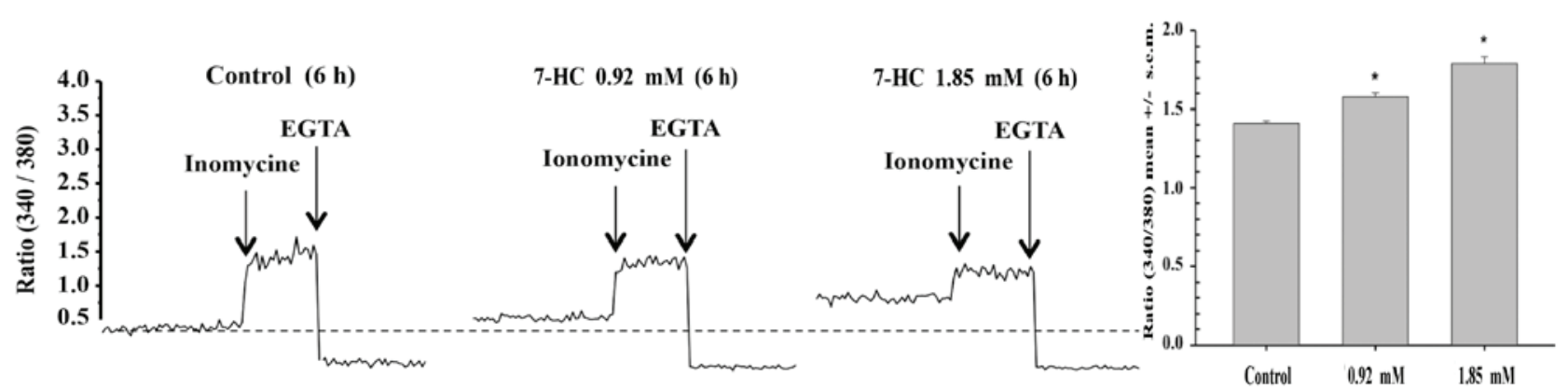

Figure 4. Calcium influx into A549 cells $\left(3 \times 10^{6}\right)$, induced by an 0.9 or $1.85 \mathrm{mM}$ solution of $7-\mathrm{HC}$ in ethanol or $3 \%$ ethanol. Cells were loaded with $4 \mu \mathrm{M}$ Fura-2 AM. Fluorescence was detected at $488 \mathrm{~nm}$, alternately exciting Fura-2 AM at 340/380 nm. Calcium influx in cells treated for (A) 3 and (B) $6 \mathrm{~h}$. Significant differences were observed between the 7-HC-treated and control cells ( $\mathrm{P}<0.05)$. 7-HC, 7-hydroxycoumarin; EGTA, ethylene glycol bis $(\beta$-aminoe thylether)-N,N,N',N'-tetraacetic acid; s.e.m., standard error of the mean.

C-3. To the best of our knowledge, single-cell microinjection has not previously been employed by other researchers in this type of study. The results indicate that 7-HC rapidly induced
C-3 activation. The concentration that induced this rapid C-3 activation effect $(1.85 \mathrm{mM})$ decreased cell viability by only $10 \%$ after $3 \mathrm{~h}$ of exposure. 
A

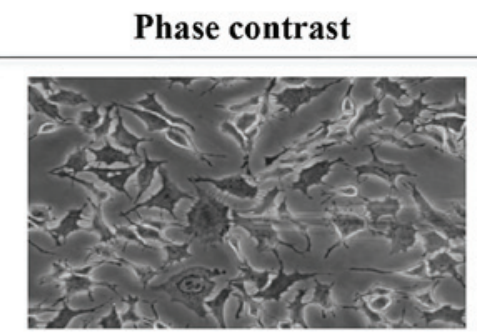

Control $120 \mathrm{sec}$

7-HC $120 \mathrm{sec}$

B

7-HC $20 \mathrm{sec}$
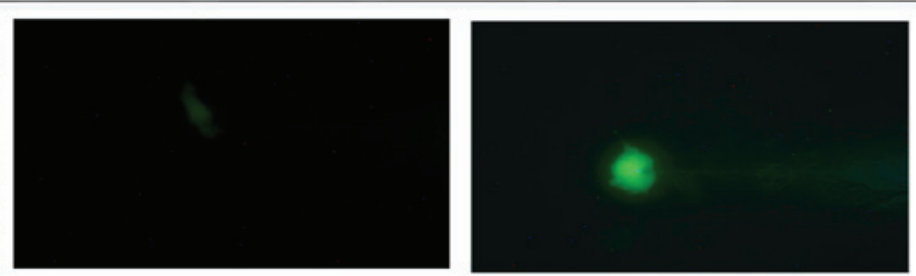

B

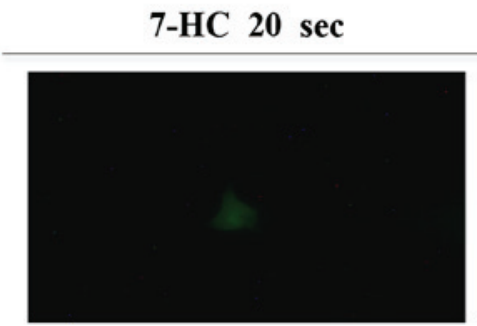

7-HC 40 sec

7-HC 120 sec
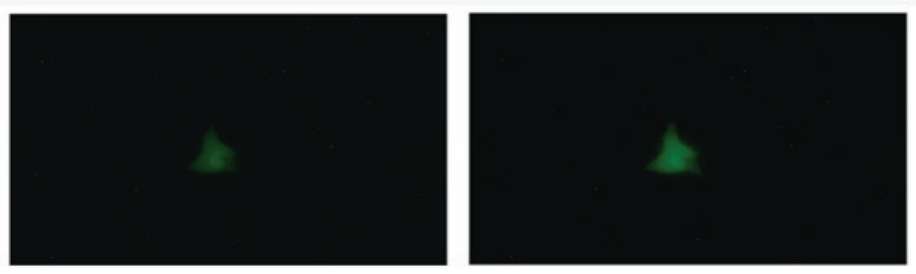

$12 \mathrm{~h}$
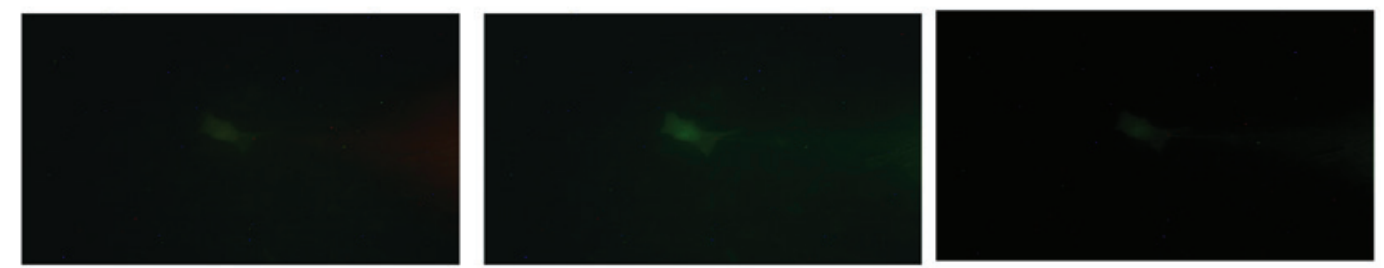

24 h
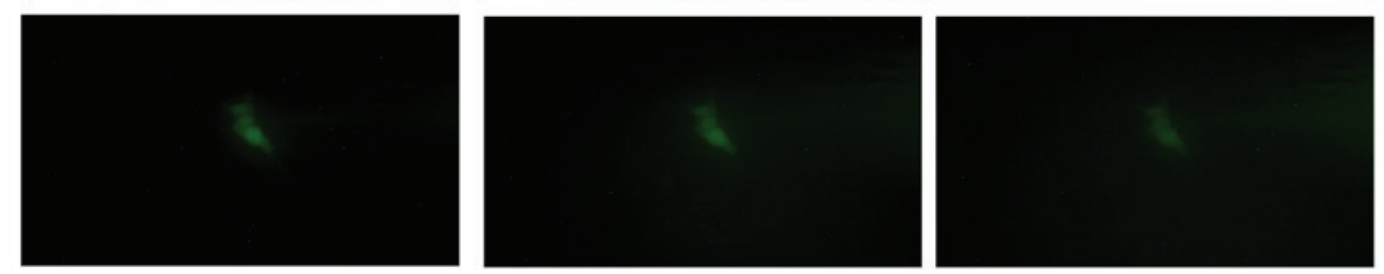

C

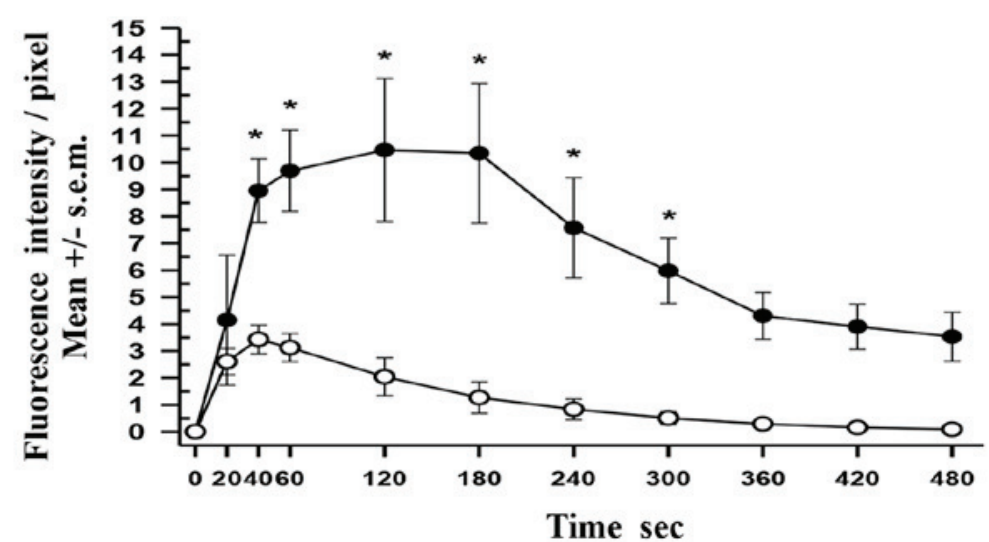

Figure 5. Single-cell microinjection of Z-DEVD-R110 substrate into cells treated with a $1.85 \mathrm{mM}$ solution of 7-HC in ethanol or 3\% ethanol (magnification, $\mathrm{x} 400$ ). (A) Representative images are shown for phase contrast imaging, and fluorescence at $520 \mathrm{~nm}$ for a control cell and a cell exposed to $7-\mathrm{HC}$ for $3 \mathrm{~h}$ (captured at $120 \mathrm{sec}$; maximal intensity was registered). (B) Post-injection photographs of cells exposed to 7-HC for 6, 12 and $24 \mathrm{~h}$, obtained at 20,40 and $120 \mathrm{sec}$ after microinjection. (C) Fluorescence intensity/pixel plot demonstrating the kinetic activity of caspase-3 in A549 cells treated with 7-HC for $3 \mathrm{~h}$. Each point represents the mean \pm standard error of the mean (s.e.m.) of three experiments. ${ }^{*} \mathrm{P}<0.05$ between 7 -HC-treated cells (filled circles) and the control group (empty circles). 7-HC, 7-hydroxycoumarin.

The majority of previous studies have employed a maximum simple coumarin concentration of $100 \mu \mathrm{M}$ and reported the reduction of viability at 24 or $48 \mathrm{~h}(10-17)$. However, it was not clear whether this rapid C-3 activation effect was induced by the binding of 7-HC with particular intracellular ligands. Zlabinger et al (27) demonstrated that in human monocytes, coumarin binding sites appeared to be present in relatively high numbers $\left(7.5 \times 10^{8} /\right.$ cell); however, their affinity was low $\left(\mathrm{K}_{\mathrm{a}} \sim 2 \times 10^{2} \mathrm{M}^{-1}\right)$. Furthermore, inhibition experiments performed with 7-HC revealed that an $\sim 4$-fold molar concentration of 7-HC was necessary to induce a $50 \%$ displacement of coumarin from its binding site (27). It may be hypothesized that the $\mathrm{C}-3$ activation effect, observed at higher concentrations compared with those previously reported, may be due to A549 cells possessing these binding sites.

Cytotoxic and cytostatic activity, in addition to the mechanisms by which these effects are produced, have been reported for a number of naturally occurring coumarins, 
such as esculetin $(11,13)$ and osthole $(16,18)$, in addition to and synthetic coumarins such as quercetin (17). However, the majority of these coumarins have not been subjected to testing beyond the pre-clinical phase, in contrast with the coumarins whose effects and pharmacokinetic properties in humans are widely known. The prompt conversion of coumarin into 7-HC, which has displayed the most relevant activity, as well as its rare toxicity among patients (7) is well documented. In 1994, Marshall et al (28) reported the testing of 7-HC in a phase I trial in which patients who received daily dosages of between 1,000 and 7,000 $\mathrm{mg}$ presented few collateral effects. It has also been reported that 7-HC is not transported by multidrug resistance-associated proteins (4-7,29). As 7-HC has been previously employed in a number of phase II clinical studies, and has already been designated an Orphan drug by the US FDA, there is a possibility of successfully conducting further studies using 7-HC combined with conventional therapy as a lung cancer treatment.

\section{Acknowledgements}

This study constitutes a partial fulfillment of the Graduate Program in Biological Sciences of the National Autonomous University of México. The authors thank Hiram Molina Espinosa for critically reading the final version of the manuscript and making valuable suggestions. Grants were obtained from the National Science and Technology Council (no. 98729) and the Research and Technological Innovation Support Program from the National University of Mexico (no. IN216812).

\section{References}

1. U.S. National Cancer Institute: Surveillance, Epidemiology, and End Results Program. SEER Stat Fact Sheets: Lung and Bronchus Cancer. http://seer.cancer.gov/statfacts/html/lungb. html. Accessed April 14, 2015.

2. U.S. National Cancer Institute: Targeted Cancer Therapies. http://www.cancer.gov/about-cancer/treatment/types/

targeted-therapies/targeted-therapies-fact-sheet. Accessed April 12, 2015.

3. U.S. Food and Drug Administration (FDA): Search Orphan Drug Designations and Approvals. http://www.accessdata.fda. gov/scripts/opdlisting/oopd/OOPD_Results_2.cfm. Accessed April 14, 2015.

4. Jain PK: Coumarin: Chemical and pharmacological profile. J App Pharm Sci 2: 236-240, 2012.

5. Casley-Smith JR and Casley-Smith JR: The pathophysiology of lymphedema and the action of benzo-pyrones in reducing it. Lymphology 21: 190-194, 1988.

6. Thornes RD, Lynch G and Seehan MV: Cimetidine and coumarin therapy of melanoma. Lancet 2: 328, 1982 .

7. Cox D, O'Kennedy R and Thornes RD: The rarity of liver toxicity in patients treated with coumarin (1,2-benzopyrone). Hum Toxicol 8: 501-506, 1989.

8. Thornes D, Daly L, Lynch G, Browne H, Tanner A, Keane F, O'Loughlin S, Corrigan T, Daly P and Edwards G; Irish Melanoma Group: Prevention of early recurrence of high risk malignant melanoma by coumarin. Eur J Surg Oncol 15: 431-435, 1989.

9. Dexeus FH, Logothetis CJ, Sella A, Fitz K, Amato R, Reuben JM and Dozier N: Phase II study of coumarin and cimetidine in patients with metastatic renal cell carcinoma. J Clin Oncol 8: 325-329, 1990.

10. Mohler JL, Gomella LG, Crawford D, Glode LM, Zippe CD, Fair WR and Marshal ME: Phase II evaluation of coumarin (1,2-benzopyrone) in metastatic prostatic carcinoma. Prostate 20: $123-131,1992$.
11. Chu CY, Tsai YY, Wang CJ, Lin WL and Tseng TH: Induction of apoptosis by esculetin in human leukemia cells. Eur J Pharmacol 416: 25-32, 2001.

12. Lopez-Gonzalez JS, Prado-Garcia H, Aguilar-Cazares D, Molina-Guarneros JA, Morales-Fuentes J and Mandoki JJ: Apoptosis and cell cycle disturbances induced by coumarin and 7-hydroxycoumarin on human lung carcinoma cell lines. Lung Cancer 43: 275-283, 2004.

13. Yang JY, Della-Fera MA and Baile CA: Esculetin induces mitochondria-mediated apoptosis in 3T3-L1 adipocytes. Apoptosis 11: 1371-1378, 2006.

14. Chuang JY, Huang YF, Lu HF, Ho HC, Yang JS, Li TM, Chang NW and Chung JG: Coumarin induces cell cycle arrest and apoptosis in human cervical cancer HeLa cells through a mitochondria- and caspase- 3 dependent mechanism and NF-kappaB down-regulation. In vivo 21: 1003-1009, 2007.

15. Alvarez-Delgado C, Reyes-Chilpa R, Estrada Muñiz E, Mendoza-Rodríguez A, Quintero-Ruiz A, Solano J and Cerbón MA: Coumarin A/AA induces apoptosis-like cell death in HeLa cells mediated by the release of apoptosis-inducing factor. J Biochem Mol Toxicol 23: 263-272, 2009.

16. Zhang L, Jiang G, Yao F, He Y, Liang G, Zhang Y, Hu B, Wu Y, Li Y and Liu H: Growth inhibition and apoptosis induced by osthole, a natural coumarin, in hepatocellular carcinoma. PLoS One 7: e37865, 2012.

17. Zheng SY, Li Y, Jiang D, Zhao J and Ge JF: Anticancer effect and apoptosis induction by quercetin in the human lung cancer line A-549. Mol Med Rep 5: 822-826, 2012.

18. Shokoohinia Y, Hosseinzadeh L, Alipour M, Mostafaie A and Mohammadi-Motlagh HR: Comparative evaluation of cytotoxic and apoptogenic effects of several coumarins on human cancer cell lines: Osthole induces apoptosis in p53-deficient H1299 cells. Adv Pharmacol Sci 2014: 847574, 2014.

19. Finn G, Creaven B and Egan D: Modulation of mitogen-activated protein kinases by 6-nitro-7-hydroxycoumarin mediated apoptosis in renal carcinoma cells. Eur J Pharmacol 481: 159-167, 2003.

20. Musa MA, Badisa VL, Latinwo LM, Patterson TA and Owens MA: Coumarin-based benzopyranone derivatives induced apoptosis in human lung (A549) cancer cells. Anticancer Res 32: 4271-4276, 2012.

21. Goel A, Prasad AK, Parmar VS, Ghosh B and Saini N: Apoptogenic effect of 7,8-diacetoxy-4-methylcoumarin and 7,8-diacetoxy-4-methylthiocoumarin in human lung adenocarcinoma cell line: Role of NF-kappa B, Akt, ROS and MAP kinase pathway. Chem Biol Interact 179: 363-374, 2009.

22. Goel A, Chhabra R, Ahmad S, Prasad AK, Parmar VS, Ghosh B and Saini N: DAMTC regulates cytoskeletal reorganization and cell motility in human lung adenocarcinoma cell line: An integrated proteomics and transcriptomics approach. Cell Death Dis 3: e402, 2012.

23. Schilling WH, Crampton RF and Longland RC: Metabolism of coumarin in man. Nature 221: 664-665, 1969.

24. Mossman T: Rapid colorimetric assay for cellular growth and survival: Applications to proliferation and cytotoxicity assay. J Immunol Methods 65: 55-63, 1983.

25. Zhang Y: Single-cell microinjection technologies. In: Single-cell Analysis: Methods and Protocols. Lindström S and Andersson-Svahn H (eds.). Humana Press, Heidelberg, pp169-176, 2012.

26. Elinos-Báez CM, León F and Santos E: Effects of coumarin and 7-OH-coumarin on bcl-2 and Bax expression in two human lung cancer cell lines in vitro. Cell Biol Int 29: 703-708, 2005.

27. Zlabinger GJ, Nöhammer C, Böhmig GA and Menzel JE: Mode of action of coumarin in immune cells. J Cancer Res Clin Oncol 120 (Suppl): S17-S18. 1994.

28. Marshall ME, Mohler JL, Edmonds K, Williams B, Butler K, Ryles M, Weiss L, Urban D, Bueschen A and Markiewicz M: An updated review of the clinical development of coumarin (1,2-benzopyrone) and 7-hydroxycoumarin. J Cancer Res Clin Oncol 120 (Suppl): S39-S42, 1994.

29. Wittgen HG, van den Heuvel JJ, van den Broek PH, Siissalo S, Groothuis GM, de Graaf IA, Koenderink JB and Russel FG: Transport of the coumarin metabolite 7-hydroxycoumarin glucuronide is mediated via multidrug resistance-associated proteins 3 and 4. Drug Metab Dispos 40: 1076-1079, 2012. 